\title{
Chronic obstructive pulmonary disease as a cardiovascular risk factor: results of a case-control study (CONSISTE study)
}

This article was published in the following Dove Press journal: International Journal of COPD

20 February 2013

Number of times this article has been viewed

\section{Michael Falola}

Department of Epidemiology, University of Alabama at Birmingham, Birmingham, AL, USA
Correspondence: Michael Falola Department of Epidemiology,

University of Alabama at Birmingham,

Birmingham, AL, USA

Email mykefalola@gmail.com

\section{To the editor}

I read with interest the article "Chronic obstructive pulmonary disease as a cardiovascular risk factor. Results of a case-control study (CONSISTE study)" by de Lucas-Ramos et al. ${ }^{1}$ In my opinion, the study did not use case-control design, despite its title.

The study participants were not selected on the basis of the outcome of interest, ie, cardiovascular disease (CVD), as is done in typical case-control studies. Rather, the study participants were selected according to the main exposure of interest which is presence or absence of diagnosis of chronic obstructive pulmonary disease with the CVD outcome of interest measured at a later point in time, thereby making it a retrospective cohort study. The authors even went further to state that "all patients had had a previous follow-up of more than 1 year." Follow-up time is a feature of cohort study and neither case-control nor cross-sectional study.

\section{Reference}

1. de Lucas-Ramos P, Izquierdo-Alonso JL, Rodriguez Gonzalez-Moro JM, Fernandez Frances J, Vaquero Lozano P, Bellón-Cano JM. Chronic obstructive pulmonary disease as a cardiovascular risk factor. Results of a case-control study (CONSISTE study). Int J Chron Obstruct Pulmon Dis. 2012;7: 679-686. 


\section{Authors' response}

\section{Pilar de Lucas-Ramos' Jose Luis Izquierdo-Alonso²}

'Respiratory Department, Hospital General Universitario Gregorio Marañón, Madrid, Spain; ${ }^{2}$ Pneumology Department, Hospital Universitario de Guadalajara, Guadalajara, Spain

Correspondence: Pilar de Lucas Ramos

Pneumology Department,

Hospital General Universitario

Gregorio Marañon, C/Dr Esquerdo 46, 28007 Madrid, Spain

Email plucasr.hgugm@salud.madrid.org

We read with interest the letter sent by Dr Michael Falola related to our study "Chronic obstructive pulmonary disease as a cardiovascular risk factor. Results of a case-control study (CONSISTE study)"1 and would like to answer that letter.

Although defining "case" as a patient with chronic obstructive pulmonary disease (COPD) and "control" as a patient without COPD, the study would seem to be directed to establish if ischemic heart disease is a risk factor for COPD, instead of if COPD is a risk factor for ischemic heart disease. In the logistic regression analysis, the ischemic heart disease was considered as the dependent variable while COPD was treated as a predictor factor, so it is correct to denominate the study as a case and controls one. With regard to the second problem, regardless of whether there was a previous followup period, otherwise necessary to ensure the diagnosis of COPD, all variables were taken simultaneously in a precise time, and therefore it is a cross-sectional study.

We consider therefore that the study methodology is correct and allows us to set the conclusions.

\section{Reference}

1. de Lucas-Ramos P, Izquierdo-Alonso JL, Rodriguez Gonzalez-Moro JM, Fernandez Frances J, Vaquero Lozano P, Bellón-Cano JM. Chronic obstructive pulmonary disease as a cardiovascular risk factor. Results of a case-control study (CONSISTE study). Int J Chron Obstruct Pulmon Dis. 2012;7:679-686.

\section{Publish your work in this journal}

The International Journal of COPD is an international, peer-reviewed journal of therapeutics and pharmacology focusing on concise rapid reporting of clinical studies and reviews in COPD. Special focus is given to the pathophysiological processes underlying the disease, intervention programs, patient focused education, and self management protocols.

\section{Dovepress}

This journal is indexed on PubMed Central, MedLine and CAS. The manuscript management system is completely online and includes a very quick and fair peer-review system, which is all easy to use. Visit http://www.dovepress.com/testimonials.php to read real quotes from published authors. 